\section{Compression stockings after deep vein thrombosis: Where is the evidence?}

\author{
Jan Schuren \\ Retired from 3M Health Care, Neuss, \\ Germany
}

\section{Introduction}

In 2014, the results were published of a randomised placebo-controlled trial to evaluate the effects of compression stockings after deep venous thrombosis (DVT to prevent a post thrombotic syndrome (PTS). 806 patients were randomly assigned. Treatment allocation was masked from patients, health-care providers, study personnel and study statisticians. The outcome was clearly defined and the surveillance was active and of clinically appropriate duration. The authors conclude that the findings of this study do not support routine wearing of elastic compression stockings after deep venous thrombosis. This study is generally referred to as the SOX-trial. ${ }^{1}$ Shortly after its publication, this study was analysed and, on behalf of the German Society of Phlebology, the authors state that wearing compression stockings after deep venous thrombosis of the leg is still advisable. ${ }^{2}$ An expert opinion, based on many years of experience and the result of two systematic reviews and meta-analyses, states that the long term use of compression stockings may reduce the incidence and severity of a post-thrombotic syndrome. ${ }^{3}$ This article reviews the literature and tries to answer the question: where is the evidence?

\section{Compression stockings after DVT to prevent PTS: Guidelines}

In 2012 a paper was published in Chest, the journal of the American College of Chest Physicians, in which evidence-based clinical practice guidelines on antithrombotic therapy and the prevention of thrombosis are provided. ${ }^{4}$ The authors suggest the use of compression stockings in patients with acute symptomatic DVT of the leg. In addition, it is suggested that compression stockings should be worn for two years and beyond that if patients have developed PTS and find the stockings helpful. Also in 2012, the UK National Institute for Health and Care Excellence (NICE) published guidelines on venous thromboembolic diseases
(VTE). ${ }^{5}$ It is recommended to offer belowknee graduated compression stockings with an ankle pressure greater than $23 \mathrm{mmHg}$ to patients with proximal DVT a week after diagnosis or when swelling is reduced sufficiently and if there are no contraindications. Patients should be advised to continue wearing the stockings for at least two years. In 2015 the NICE guidelines are updated and now it is recommended that elastic graduated compression stockings should not be offered to prevent post-thrombotic syndrome or VTE recurrence after a proximal DVT. ${ }^{6}$ Shortly after that, also the 2012 US-guidelines are updated. ${ }^{7}$ For patients with acute DVT of the leg, it is now suggested that compression stockings to prevent PTS should not be routinely used. In other countries, like Australia, New Zealand, Germany, France and the Netherlands, guidelines still recommend the use of graduated compression stockings after DVT to prevent PTS. ${ }^{8-11}$

\section{Compression stockings after DVT to prevent PTS: systematic reviews and meta-analyses}

After the publication of the SOX-trial, five systematic reviews with meta-analyses were published in which the SOX-trial was included. ${ }^{12-16}$ This high number of reviews not only illustrates the increasing recognition of PTS as a long-term complication of DVT, it also demonstrates a clear need for evidence-based information on the best treatment. In addition, the number of reviews demonstrates the confusion among clinicians on this complication with a significant impact on quality of life and major health economic implications. Baldwin et al. state that up to half of the patients with proximal DVT will develop PTS despite optimal anticoagulant therapy. ${ }^{17}$ Although much has been published to date, the reviews of the recent literature are very uniform in their conclusions. They can best be summarised with some of them, which are listed below: i) the findings should be interpreted with caution and hence more largescale and well-designed RCT's are still warranted; ${ }^{12}$ ii) the evidence is too weak to draw a reliable conclusion and further randomised, double-blind, placebo-controlled multicentre trials with larger sample size are needed; ${ }^{13}$ iii) use of elastic compression stockings does not significantly reduce the development of post thrombotic syndrome, but more study is needed; ${ }^{14}$ iv) low-quality evidence suggests that elastic compression stockings may reduce the occurrence of PTS after DVT but large RCT's are needed to
Correspondence: Jan Schuren, Grotestraat 34, 6067 BR Linne, The Netherlands.

E-mail: jan.schuren@gmail.com

Conflicts of interest: JS is a retired $3 \mathrm{M}$ employee and invented and co-developed the $3 \mathrm{M}$ Coban 2 Layer compression systems and holds a master's degree in evidence-based health care from the University of Oxford.

Conference presentation: International Compression Club (ICC) Meeting, Paris, 2017.

This work is licensed under a Creative Commons Attribution 4.0 License (by-nc 4.0).

(C) Copyright J. Schuren, 2018

Licensee PAGEPress, Italy

Veins and Lymphatics 2018; 7:7636

doi:10.4081/vl.2018.7636

confirm these findings because of current lack of high quality evidence and considerable heterogeneity. ${ }^{16}$

Burgstaller et al. summarise their findings with the statement that there is evidence favouring compression stockings, but that there is also evidence showing no benefit of compression stockings. ${ }^{15}$

\section{Discussion}

The conclusions of the presented reviews are obvious; more research on compression to prevent PTS is needed. However, after the SOX-trial with over 800 patients included, it can be questioned how realistic the expectation is that in the near future a similar large double-blinded randomised controlled trial will be executed that fulfils all needs. In a journal editorial in the issue in which one of the mentioned reviews was published, ${ }^{15}$ Ten Cate-Hoek states that, besides compression therapy, more therapeutic options are needed for prevention and treatment of PTS. She suggests to take action and to assess the possibilities ahead of us, instead of trying to solve the current conundrum around elastic compression therapy. ${ }^{18}$ For the time-being, the only reasonable and unfortunately not evidence-based direction lies in a quote from the Christian author Elisabeth ElliotHoward (1926-2015): don't dig up in doubt what you planted in faith.

\section{References}

1. Kahn SR, Shapiro S, Wells PS, et al. for the SOX trial investigators. 
Compression stockings to prevent postthrombotic syndrome: a randomized placebo-controlled trial. Lancet 2014;379:31-8.

2. Schwahn-Schreiber C, Marshall M, Wienert V, et al. Wearing compression stockings after deep venous thrombosis of the leg is still advisable: analysis of a publication in The Lancet, December 2013. Phlebologie 2014;43:144-7.

3. Partsch H. Compression and deep vein thrombosis. Veins and Lymphatics 2016;5:22-3.

4. Kearon C, Akl EA, Comerota AJ, et al. Antithrombotic therapy for VTE disease. Chest 2012;141:e419S-94S.

5. National Institute for Health and Care Excellence (NICE). Venous thromboembolic diseases: the management of venous thromboembolic diseases and the role of thrombophilia testing. Clinical guideline [CG144]: published June 2012.

6. National Institute for Health and Care Excellence (NICE). Venous thromboembolic diseases: the management of venous thromboembolic diseases and the role of thrombophilia testing. Clinical guideline [CG144]: published June 2012, updated November 2015.
7. Kearon C, Akl EA, Ornelas J, et al. Antithrombotic therapy for VTE disease: CHEST Guidelines and expert panel report. Chest 2016;149:315-52.

8. Australian and New Zealand Society for Vasular Surgery. Guidelines deep venous thrombosis; 2015. Available from: www.anzsvs.org.au

9. AWMF, Arbeitsgemeinschaft der Wissenschaftlichen Medizinischen Fachgesellschaften e.V. S2-Leitlinie: Diagnostik und Therapie der Venenthrombose und der Lungenembolie. AWMF LeitlinienRegister Nr. 065/002; 2015.

10. Haute Autorité de Santé (HAS). La compression médicale dans le traitement de la maladie thrombo-embolique veineuse; Décembre 2010.

11. NHG-werkgroep diepe veneuze trombose en longembolie. NHG Standaard: diepe veneuze trombose en longembolie. Huisarts Wet 2015;58:26-35.

12. Tie HT, Luo MZ, Luo MJ, et al. Compression therapy in the prevention of postthrombotic syndrome: a systematic review and meta-analysis. Medicine 2015;94:1-8.

13. Jin YW, Ye H, Li FY, et al. Compression stockings for prevention of postthrom- botic syndrome: a systematic review and meta-analysis. Vasc Endovasc Surg 2016;50:328-34.

14. Subbiah R, Aggarwal V, Zhao H, et al. Effect of compression stockings on post-thrombotic syndrome in patients with deep vein thrombosis: a metaanalysis of randomised controlled trials. Lancet Haematol 2016;3:293-300.

15. Burgstaller JM, Steurer J, Held U, Amann-Vesti B. Efficacy of compression stockings in preventing postthrombotic syndrome in patients with deep venous thrombosis: a systematic review and metaanalysis. Vasa 2016;45:141-7.

16. Appelen D, van Loo E, Prins MH, et al. Compression therapy for prevention of post-thrombotic syndrome. Cochrane Database Syst Rev 2017;9:CD004174.

17. Baldwin MJ, Moore HM, Rudarakanchana N, et al. Post-thrombotic syndrome: a clinical review. J Thromb Haemost 2013;11:795-805.

18. Ten Cate-Hoek A. Efficacy of compression for the prevention of post-thrombotic syndrome: an unsolved clinical conundrum. Vasa 2016;45:85-6. 